\title{
VEIAS SOLEARES: BASES ANATÔMICAS E SEU PAPEL NA ORIGEM DA TROMBOSE VENOSA PROFUNDA EM MEMBRO INFERIOR
}

\author{
Carlos Miguel Gomes Sequeira*, Yara Juliano, Neil Ferreira Novo, Rubens Carlos Mayall [in memoriam], Fausto Miranda Junior \\ Trabalho realizado na Faculdade de Medicina da Universidade Federal do Rio de Janeiro e na Escola Paulista de Medicina da Universidade Federal de São Paulo
}

\begin{abstract}
RESUMO
OBjEtivo. Estudar o número, a setorização e a terminação das veias soleares.

Métodos. Em 100 pernas de 50 cadáveres, excluídos aqueles com alterações congênitas ou adquiridas dos membros inferiores, foram realizadas, a fresco, na região crural posterior, dissecções anatômicas minuciosas, estratigráficas. Após o rebatimento da pele, foram realizadas a individualização das veias superficiais e perfurantes, rebatimento da tela subcutânea e da fáscia, individualização e rebatimento dos músculos gastrocnêmio e plantar, desinserção tibial do músculo sóleo, individualizaçãa das veias soleares e o estudo morfométrico. A região foi dividida em seis setores: súpero-medial, súpero-lateral, médiomedial, médio-lateral, ínfero-medial e ínfero-lateral. No estudo estatístico utilizaram-se os testes não-paramétricos Wilcoxon e Friedman.
\end{abstract}

Resultados. Foram encontradas 4.679 veias soleares. O setor com maior número de velas soleares foi o súpero-lateral com 1.529 veias (32,7\%), seguido do médio-medial com 1.256 veias $(26,8 \%)$ e do médio-lateral com 975 veias $(20,8 \%)$. As terminações ocorreram em veias comunicantes (I.207 veias - $25,8 \%$ ), veias tibiais posteriores (964 veias - $20,6 \%)$, veias fibulares $(709$ veias - 15,2\%) e em mais 32 tipos (1799 veias - 38,4\%).

\author{
* Correspondência \\ Rua Barão do Bananal, 233 \\ Cascadura, Rio de Janeiro/ RJ - \\ Brasil \\ Cep: $21380-330$ \\ Telefax: (21) 2592-6406 \\ cmgsequeira@ig.com.br
}

Conclusão. A drenagem venosa do músculo sóleo é realizada por um grande número de veias soleares, freqüentemente localizadas nos setores súpero-lateral, médio-medial e médio-lateral, terminando comumente em veias tibiais posteriores e fibulares e, em veias comunicantes.

Unitermos: Veias. Músculo esquelético. Extremidade inferior. Humanos. Anatomia.

\section{INTRODUÇÃO}

O grande desenvolvimento dos músculos da panturrilha é especificamente uma característica da espécie humana e está intimamente associado à postura ereta. O músculo tríceps sural é composto por dois músculos: um superficial, o gastrocnêmio e um profundo, o sóleo, situando-se entre eles o músculo plantar. 0 músculo sóleo é um músculo muito largo e espesso situado anteriormente ao músculo gastrocnêmio. E responsável principalmente pela flexão plantar do pé, atuando poderosamente na marcha e no salto e, secundariamente, pela flexão da perna ${ }^{1-3}$. Loitz' ressaltou que o músculo sóleo tem sido motivo de um número crescente de investigações que comprovam estar ele relacionado à manutenção postural, estabilização e propulsão do membro inferior, durante a locomoção.

O sistema venoso profundo é responsável por cerca de 90\% da drenagem venosa dos membros inferiores, sendo as veias musculares da panturrilha juntamente com as veias tibiais posteriores, fibulares, tibiais anteriores e poplítea as responsáveis pela formação da bomba músculo-venosa da panturrilha, principal sistema aspirante-propulsor do membro inferior ${ }^{4}$, sendo o retorno venoso da perna, na posição em pé, muito eficaz pela contração do músculo sóleo.

Abramova e Chilaya ${ }^{5}$ demonstraram que geralmente no interior do músculo sóleo existem de três a oito seios venosos longitudi- nais, mais freqüentemente três: um lateral e um intermédio, que terminam em veias fibulares, e um medial, que termina em veias tibiais posteriores. Segundo Ukhov', as veias soleares formam três troncos coletores em 67\% dos casos: um medial, um central e um lateral, predominando em 16\% o coletor medial, em II\% o central e em $5 \%$ o lateral, bilateralmente, relacionando tal disposição à divisão do músculo, por lâminas tendinosas, em três porções. No terço superior do músculo saem dele de duas a quatro veias para terminarem nas veias tibiais posteriores, sendo mais raro a presença de um tronco único ou de mais de quatro veias.

Mayall et al. ${ }^{6}$, após dissecarem dez membros inferiores de cadáveres formolizados observaram a presença de quatro a 19 veias soleares, por perna, estando uma a dez veias soleares terminando em veias tibiais posteriores, e uma a seis veias soleares lançando-se em veias fibulares, além de, em alguns casos, afluirem também em veias tibiais anteriores, poplíteas, geniculares, safena parva, gastrocnêmias medial e lateral. Em Sequeira et al. ${ }^{7}$, os autores compararam os resultados quantitativos das dissecções dessas veias, em pernas formolizadas (média de 7,2 veias por perna), com as dissecções a fresco (média de 46,8 veias por perna), concluindo que a diferença nessas médias deveu-se ao método usado nesse estudo.

Estudos de outros autores ${ }^{5,8-10}$ evidenciaram a presença de trombose venosa profunda (TVP) em veias da panturrilha, prin- 
Sequeira CMG et al.

cipalmente nas veias soleares sendo que dois terços dos pacientes com trombo-embolismo pulmonar (TEP) não manifestam sintomas previamente ${ }^{8}$, que possibilitem não só o diagnóstico precoce, como um tratamento oportuno e eficaz. Zicot e Caro"l referiram a ocorrência de trombose nas veias da panturrilha, mais freqüente no músculo sóleo que no músculo gastrocnêmio e, principalmente nas veias maiores, justificando tal diferença pelo fato de a velocidade do sangue ser mais baixa no músculo sóleo.

O desenvolvimento da cirurgia vascular e dos diferentes métodos de investigação por imagem fez aumentar a importância e a necessidade de conhecimento anatômico detalhado sobre as veias profundas dos membros inferiores, principalmente das veias da panturrilha e nestas, maior ênfase nas veias soleares, porém são raros os estudos anatômicos descritos em livros e artigos científicos, o que contrasta com a grande importância clínica dessas veias como o local mais freqüente de origem de trombos.

Objetivos: estudar o número, a setorização e terminação das veias soleares.

\section{Métodos}

Neste trabalho foram realizados estudos diretos, macroscópicos, de 100 pernas de 50 cadáveres humanos obtidos no Instituto Médico Legal Afrânio Peixoto, no Estado do Rio de Janeiro. O projeto de pesquisa foi aprovado pelo Comitê de Ética em Pesquisa da Universidade Federal de São Paulo em 13/ 09/2002.

Sequeira' ${ }^{12}$ realizou estudos com identificação de idade, sexo, cor, biótipo, lateralidade, altura perna-pé, comprimento e largura do músculo sóleo, nos quais a análise estatística não demonstrou índice de significância para esses parâmetros, por isso aqui foi estudada uma amostra total de 100 pernas. Nos critérios de inclusão constaram cadáveres frescos (não formolizados), de indigentes, adultos, ambos os sexos, todas as cores, sem malformações congênitas ou outras alterações nos membros inferiores; excluindo-se os membros com presença de cicatrizes cirúrgicas, traumatismos ou outras lesões.

Os estudos anatômicos foram realizados na região posterior da perna, através de dissecções minuciosas, desde a pele até as estruturas situadas na parte profunda quais sejam: os músculos, as artérias e as veias principais. Inicialmente o cadáver foi colocado na posição de decúbito ventral, sendo traçadas as linhas de incisões cutâneas e marcando-se as linhas transversais limitantes da região a ser dissecada'2. A seguir, traçou-se a linha longitudinal de localização paramediana medial, para que a incisão se desviasse do trajeto da veia safena parva (Figura I). A pele foi então dissecada e rebatida medial e lateralmente. No tempo seguinte foram individualizadas as veias do subcutâneo, principalmente aquelas que perfuravam a fáscia crural posterior. Em seguida, esta fáscia foi incisada e as veias perfurantes foram seguidas para identificar aquelas que estivessem relacionadas com o ventre do músculo sóleo; desinseriu-se a porção tibial do músculo sóleo, para se ter um acesso mais amplo à parte profunda da região posterior da perna, identificando-se e individualizando-se todas aquelas veias que emergiam das margens e da face anterior do músculo sóleo. Durante a dissecção efetuada em cada perna, foram realizados os seguintes procedimentos: I) localização das veias soleares; 2) contagem dessas veias; 3) observação das terminações dessas veias; 4) estudo morfométrico; 5) documentação fotográfica.

Em relação à localização e à contagem das veias soleares, para nortear este estudo, foi considerado como veia solear toda veia que emergia do músculo sóleo por qualquer das margens ou faces de seu ventre muscular ou tendão, pois nessa situação ela estará de alguma maneira realizando uma parte da drenagem venosa desse músculo.

Com a finalidade de melhor localizar as veias soleares na região posterior da perna, já que o seu número foi bastante elevado, Sequeira'2 dividiu essa região em seis setores denominados, no sentido próximo-distal: súpero-medial, súpero-lateral, médiomedial, médio-lateral, ínfero-medial e ínfero-lateral (Figura I).

As medidas foram realizadas usando-se três instrumentos aferidos: o compasso de toque ou de pontas rombas, tipo Martin, uma trena de fabricação Stanley, de dois metros e um paquímetro analógico universal de precisão de fabricação Mitutuyo, de 200/8" $\mathrm{mm} / \mathrm{pol}$. Todas as medidas foram obtidas em escala centimetral (sistema CGS). Sempre que necessário usou-se uma lupa frontal de 10 dioptrias (magnificação 2,5 x). A documentação fotográfica foi realizada com uma câmera de fabricação Canon FTb QL FI com o uso de duas objetivas.

Foram utilizados os seguintes testes estatísticos:

I- Teste de Wilcoxon para duas amostras não independentes ${ }^{13}$, com a finalidade de comparar os segmentos medial e lateral em relação ao número de veias soleares;

2- Análise de variância por postos de Friedman ${ }^{13}$ com o objetivo de comparar os números de veias soleares dos setores superiores, médios e inferiores, em separado para os segmentos medial e lateral.

Em todos os testes fixou-se o nível de significância em 0,05 ou $5 \%$, assinalando-se os valores significantes com um asterisco.

\section{Resultados}

Os estudos realizados nas 100 pernas dissecadas mostraram uma grande quantidade de veias relacionadas ao músculo sóleo. Os resultados estão na seguinte seqüência:

I. Número de veias soleares;

2. Localização e setorização das veias soleares;

3. Terminação das veias soleares;

4. Correlação entre os parâmetros:

4.I. Número de veias soleares $x$ setores $x$ segmentos

4.2. Número de veias soleares $x$ terminações $x$ setores.

\section{Número de veias soleares (Figura I)}

Nas 100 pernas dissecadas foram observadas 4.679 veias. 0 número médio de veias por indivíduo foi de 93,6 veias. O número médio de veias soleares por perna foi de 46,8.

\section{Localização e setorização das veias soleares (Figura I e Tabela I).}




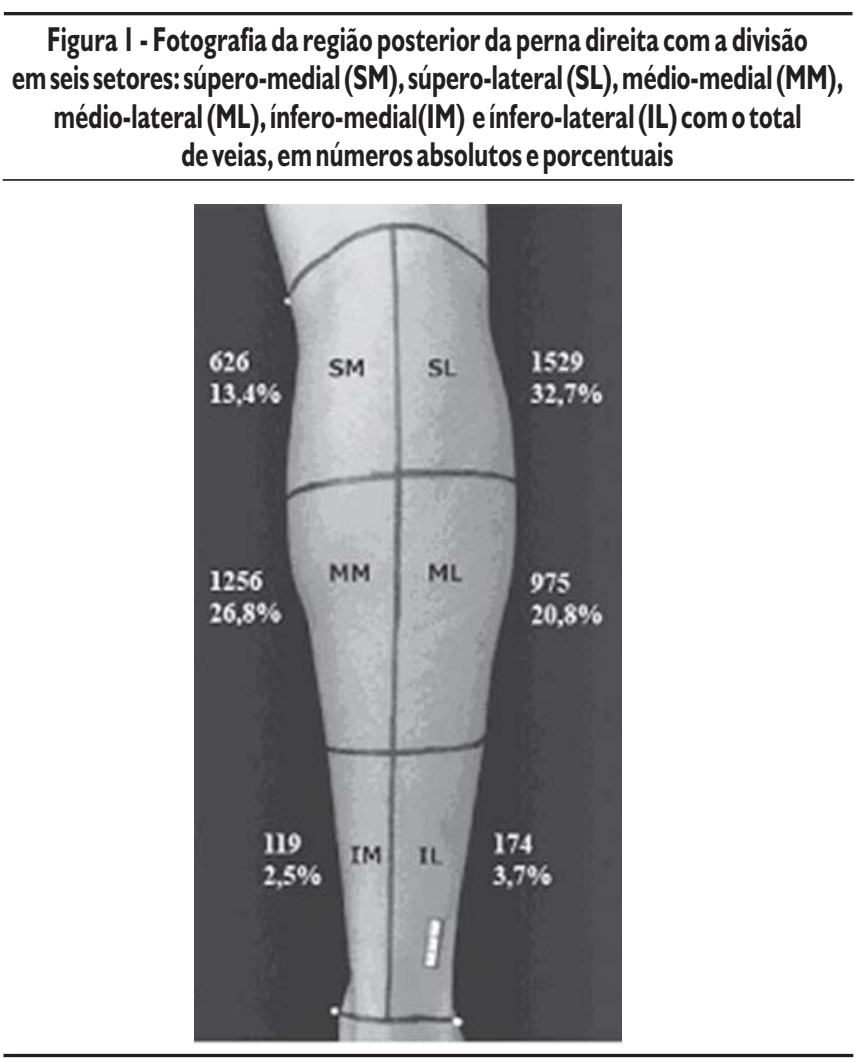

Em relação à segmentação longitudinal e considerando-se a amostra total, das 4.679 veias encontradas, 2.678 veias $(57,2 \%)$ estavam no segmento lateral e 2.00 I veias $(42,8 \%)$ no segmento medial. Quanto à segmentação transversal, os segmentos com maior número de veias foram o médio, com 2.23 I veias (47,7\%), o superior com 2. 155 veias $(46,1 \%)$ e o inferior com 293 veias (6,3\%). Na amostra total, os setores com maior número de veias foram o súperolateral (SL) com 1.529 veias (32,7\%) e o médio-medial com 1.256 $(26,8 \%)$ veias, seguidos dos setores médio-lateral com 975 veias $(20,8 \%)$, súpero-medial 626 veias $(13,4 \%)$, ínfero-lateral 174 veias $(3,7 \%)$ e ínfero-medial com 119 veias (2,5\%).

\section{Terminação das veias soleares}

$\mathrm{Na}$ amostra total, as terminações das veias soleares ocorreram mais freqüentemente em veias comunicantes, I.207 (25,8\%); nas tibiais posteriores, 964 (20,6\%); nas fibulares, 709 (15,2\%); nas veias da cabeça lateral do músculo gastrocnêmio, 333 veias (7,1\%); nas veias da cabeça medial do músculo gastrocnênio, 283 veias $(6,0 \%)$ e, mais 30 tipos diferentes de terminações com freqüências menores $(25,3 \%)$.

\section{Correlação entre os parâmetros}

4.I. Número de veias soleares $x$ setores $x$ segmentos

$O$ teste de Wilcoxon demonstrou significância nos setores superiores, com o segmento lateral apresentando maior número de veias do que o medial, ocorrendo o inverso nos setores médios, isto é, o medial apresentou mais veias do que o lateral. Não houve significância nos setores inferiores.

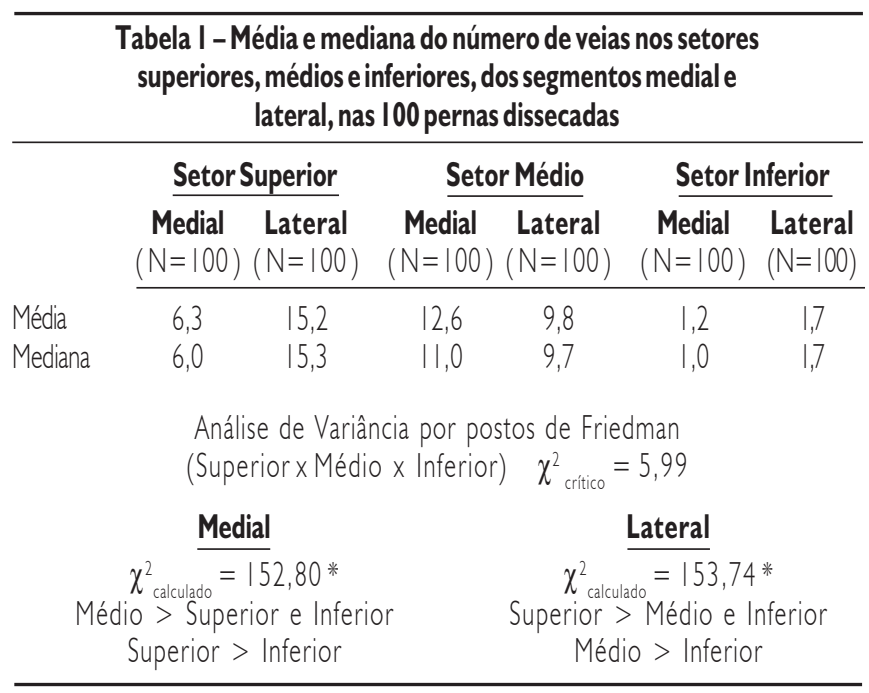

* índice significante

Figura 2 - Fotografia da região posterior de duas pernas direitas. A-músculo sóleo(MS) e I 2 veias soleares terminando em veias tibiais posteriores (VTP);

B- músculo sóleo (MS) desinserido da tíbia, com o anel solear aberto, visibilizando-se as veias soleares(VS), terminando sete delas, em veias fibulares (VF), cinco, em veias tibiais posteriores (VTP), duas em veia poplítea (VP) e duas em veia gastrocnêmia lateral (VGL)

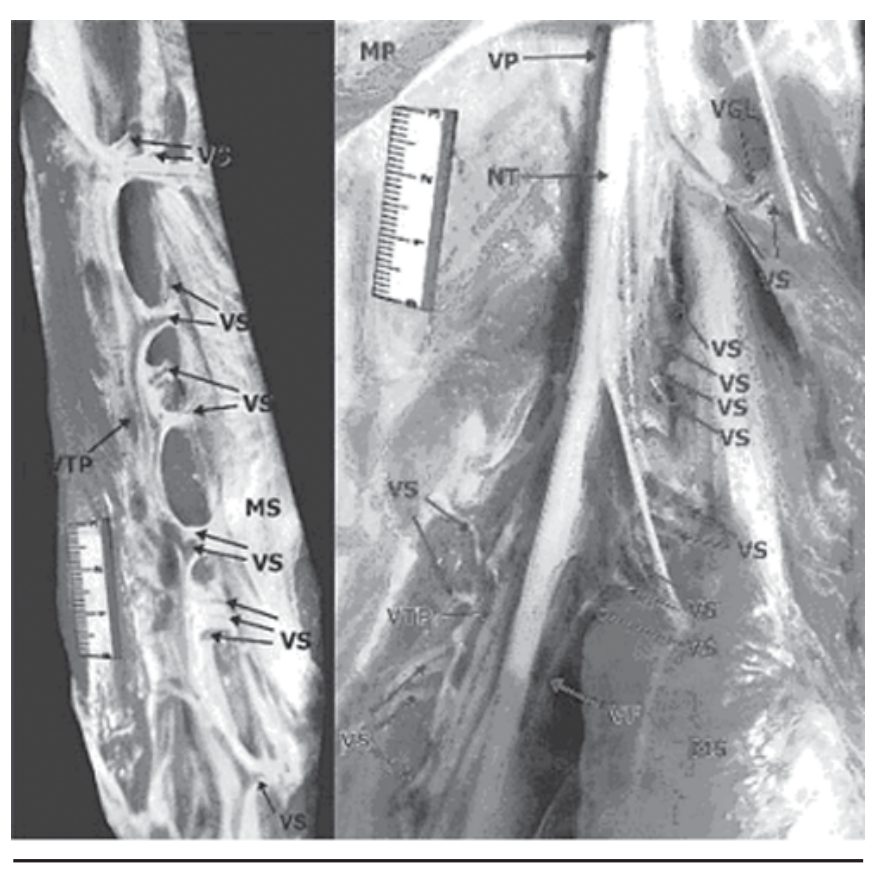

teste de Análise de Variância por postos de Friedman, ao comparar os setores superior, médio e inferior nos segmentos medial e lateral, apresentou significância tanto no medial como no lateral. No medial, o setor médio apresentou mais veias do que o superior e inferior, tendo o superior mais veias do que o inferior. No lateral, o superior teve mais veias do que o médio e o inferior, tendo o médio mais veias do que o inferior (Tabela I). 


\subsection{Número de veias soleares $x$ terminações $x$ setores}

A maior freqüência de terminações de veias soleares ocorreu em veias comunicantes, dos sistemas superficial ou profundo, seguidas das terminações em veias tibiais posteriores, veias fibulares e outras, num total de 35 tipos diferentes de terminações das veias soleares. Nos 14 tipos mais freqüentes de terminação das veias soleares $(74,7 \%)$, aquelas ocorridas em veias comunicantes são mais freqüentes nos setores $I M, M L$ e IL; em veias tibiais posteriores, SM e MM; em veias fibulares, SL; em comunicante e tibial posterior, IM; em comunicante e fibular, ML; no tronco tíbiofibular, SL; em veia gastrocnêmia lateral, SL; em veia safena parva, IL; em veia genicular inferior lateral, SL; em veia gastrocnêmia medial, SM e em veia safena magna, IM (Figura 2).

\section{Discussão}

Após a revisão dos trabalhos encontrados na literatura e dos estudos realizados nas 100 pernas dissecadas, foram confrontados os resultados encontrados em ambos.

Estudos anatômicos:

\section{Número de veias soleares}

A maioria dos autores que estudou as veias soleares não fez referência ao número total de veias por perna ou por indivíduo. Abramova e Chilaya $^{5}$ observaram três veias soleares, dispostas longitudinalmente, sendo uma lateral e uma intermédia, ambas terminando em veias fibulares, e uma medial terminando em veias tibiais anteriores, corroboradas por Kwakye ${ }^{14}$, que afirma existirem outras veias soleares menores. Igualmente, Ukhov ${ }^{4}$ refere que as veias soleares formam três troncos coletores, um medial, um central e um lateral. Esta disposição foi encontrada bilateralmente, saindo de duas a quatro veias na parte superior do músculo, sendo rara a presença de um tronco venoso ou mais que quatro veias. Mayall et al. ${ }^{6}$, após a dissecção de dez membros inferiores de cadáveres formolizados, encontraram veias soleares variando de quatro a 19 por perna, estando de uma a 10 veias soleares terminando em veias tibiais posteriores, e de uma a seis veias terminando em veias fibulares, encontrando em alguns casos veias soleares terminando em veias tibiais anteriores, poplíteas e geniculares.

A noção clássica de que no sistema venoso profundo toda artéria é acompanhada de veias, as quais geralmente são duplas e denominadas satélites dessas artérias ${ }^{2,13,15-16}$, foi demonstrada por Raveendran e Kumaragama ${ }^{17}$, descrevendo que todas as artérias soleares eram acompanhadas por veias satélites; por analogia e, considerando somente as veias que acompanhavam as artérias soleares, poder-se-ia então afirmar que onde eles encontraram de 7,12 a 19,48 veias soleares, haveria de 14,24 a 38,96 veias soleares. Podemos inferir ainda que além das veias soleares, satélites das artérias soleares, há um número variável de veias soleares comunicantes que se somam a esse número total de veias do músculo sóleo.

A grande diferença entre o número de veias soleares citado na literatura e o encontrado no trabalho de Sequeira ${ }^{12}$ deveu-se pri- meiramente à definição aqui adotada para veia solear. Com base nesta definição, passou-se a considerar como veias soleares aquelas que terminaram em veias principais, como tibiais posteriores, fibulares e poplítea, como citado na literatura, bem como as que terminaram em outras veias tronculares, musculares e comunicantes profundas, além das veias comunicantes perfurantes que terminaram em uma veia superficial. Apesar disso, o número de veias observadas foi ainda maior do que aquele inferido acima, o que provavelmente se deve aos critérios utilizados no trabalho para a dissecção, pois o autor, em trabalhos anteriores, quando observou pernas dissecadas pelos alunos dos cursos de graduação em medicina, estudos esses realizados em cadáveres formolizados, encontrou um número muito pequeno de veias soleares, o qual se assemelhava ao encontrado nas descrições da literatura ${ }^{4-5,14}$. Quando realizadas dissecções também em pernas de cadáveres formolizados existentes nos laboratórios de anatomia, em função de uma técnica mais apurada e objetiva para o tema ${ }^{6-7}$, já encontrou um número maior de veias soleares que variou de 4 a 19, porém ainda inferior ao observado em Sequeira ${ }^{12}$. No estudo realizado por Sequeira et al. ${ }^{7}$, no qual comparou-se as dissecções em pernas formolizadas e não formolizadas, os autores sugeriram que nas estruturas formolizadas, pelo grande poder de penetração do formol e pela desidratação tecidual, há retração, enrijecimento e grande aderência entre as estruturas sintópicas, tornando muito difícil, mesmo com técnica mais apurada, reconhecer e, principalmente, individualizar através da observação macroscópica direta veias muito finas e de paredes delicadas, o que faz com que não sejam percebidas e seccionadas ou rompidas durante o processo dissectivo, propiciando a obtenção de números certamente inferiores àqueles encontrados no vivo. Outros fatores importantes a serem considerados são a técnica microcirúrgica empregada e sem dúvida a experiência adquirida ao longo de 20 anos de estudos na panturrilha: anatômicos, flebográficos, ultra-sonográficos, clínicos e cirúrgicos.

Com base nesse conhecimento, Sequeira ${ }^{12}$ resolveu então realizar novos estudos dissectivos nessa região, agora em cadáveres frescos, usando técnica diferenciada e instrumentos de microdissecção, encontrando 4.679 veias, sendo o número médio por indivíduo 93,6 e o número médio por perna, 46,8 veias, o que superou todos os achados anteriores e, com certeza, muito se aproxima da realidade do paciente.

\section{Localização e setorização das veias soleares:}

Os autores que estudaram as veias soleares não fizeram referência ao número total de veias soleares por perna. Para melhor localizar as veias soleares, bem como realizar um estudo de correlação, Sequeira' ${ }^{12}$ dividiu essa região posterior em setores que propiciassem localizar essas veias tanto no eixo próximo-distal quanto no eixo médio-lateral, obtendo-se seis setores denominados: súpero-medial, súpero-lateral, médio-medial, médio-lateral, ínfero-medial e ínfero-lateral. A distribuição das veias soleares em relação à segmentação longitudinal foi mais freqüente no segmento lateral seguido do segmento medial. Quanto à segmentação trans- 
versal, os segmentos com maior número de veias foram o médio, seguido do superior e do inferior. Quanto à setorização, os setores com maior número de veias foram o súpero-lateral e o médiomedial seguidos dos setores médio-lateral, súpero-medial, ínferolateral e ínfero-medial. Quando se observa a Figura I, se comprova facilmente que a maior freqüência de veias soleares nos setores SL, MM e ML deve-se à presença, neles, de mais ventre do músculo sóleo.

\section{Terminação das veias soleares}

$K_{\text {Kwakye }}{ }^{14}$ e van Limborgh e Kwakye ${ }^{16}$ estudaram 45 pernas, relatando que as veias soleares estão divididas em dois grupos principais: tibial posterior e fibular. O grupo fibular é constituído por duas veias soleares longitudinais maiores: uma lateral e uma intermédia que terminam superiormente na veia fibular e o grupo tibial posterior, por diversas pequenas veias, terminando isoladamente nas veias tibiais posteriores.

As terminações das veias soleares freqüentemente encontradas foram em veias comunicantes, em veias tibiais posteriores, em veias fibulares, em veias da cabeça lateral do músculo gastrocnêmio, em veias da cabeça medial do músculo gastrocnêmio, somando $74,7 \%$ e em mais 30 tipos diferentes de terminações $(25,3 \%)$ com freqüências menores. Pode-se então afirmar que a maior parte da drenagem do músculo sóleo é realizada para esses cinco tipos citados. Desse total, de 35 tipos diferentes de terminações, 14 tipos somam $96 \%$ de todas as veias soleares encontradas e somente $4 \%$ pertencem aos outros 21 tipos. Nos 14 tipos mais freqüentes de terminação das veias soleares, aquelas ocorridas em veias comunicantes são mais freqüentes nos setores $\mathrm{IM}, \mathrm{ML}$ e IL; em veias tibiais posteriores, SM e MM; em veias fibulares, SL; em veia gastrocnêmia lateral, SL e veia gastrocnêmia medial, SM.

$\mathrm{Na}$ amostra total, as terminações das veias soleares ocorreram mais freqüentemente em veias comunicantes, seguidas das tibiais posteriores, fibulares, veias da cabeça lateral do músculo gastrocnêmio, veias da cabeça medial do músculo gastrocnênio e, mais 30 tipos diferentes de terminações com freqüências menores.

\section{Correlações clínicas:}

Zicot e Caro" encontraram trombose venosa na panturrilha mais freqüente no músculo sóleo do que no músculo gastrocnêmio, com trombos de diâmetros que variaram de 0,2 a $0,5 \mathrm{~cm}$. Um outro fato importante é que sendo o músculo sóleo um músculo de suporte e estabilização, a sua estrutura venosa intramuscular em arcadas anastomóticas, lentifica o fluxo venoso o que justifica os relatos desses autores de que a TVP é, devido a isso, mais freqüente e, em até sete vezes, no músculo sóleo que no gastrocnêmio.

Sevitt e Gallagher ${ }^{8}$ observaram, à necrópsia, a presença de trombose venosa sem embolia pulmonar em $65 \%$ dos casos estudados, sendo mais freqüente em veias intramusculares da panturrilha em 74\%, localizando-se em veias soleares em $67 \%$ dos casos, sendo os primeiros a relatar que as veias soleares são o local mais freqüente de TVP. Em um grupo no qual houve embolia pulmonar, todos os casos tiveram TVP, tendo este ocorrido bilateralmente. Esse estudos reafirmam os relatos de que a maioria dos casos de TEP ocorrem sem a presença de quadros clínicos prévios.

Abramova e Chilaya ${ }^{5}$ relataram a presença de trombose em veias soleares, originando TEP, em 19 de seus 43 casos que apresentavam trombos nos seios venosos localizados no músculo sóleo. A utilização de uma técnica flebográfica com a finalidade de demonstrar além das veias profundas dos membros inferiores, as veias soleares, na ausência ou presença de trombose, concluíram que na maioria dos pacientes a trombose começava nas veias soleares ${ }^{18-19}$. Foi observado também que o contraste injetado antes da operação desaparecia rapidamente das veias soleares e que esse tempo foi o mesmo (um minuto) nas veias tibiais posteriores, antes e durante a operação, enquanto nas veias soleares foi de 4,5 minutos antes e 8,5 minutos durante a operação, o que indicou que a estase nessas veias está significativamente aumentada durante a operação o que pode explicar a alta incidência de TVP iniciada á19.

Mayall et al. ${ }^{20}$, Mayall et al. ${ }^{6}$ e Mayall et al. ${ }^{21}$ em um estudo de 3.599 flebografias em membros inferiores observaram varizes de veias soleares em 1.420 exames. Sequeira et al. ${ }^{22}$, estudando os exames de 100 pernas de pacientes submetidas à flebografia, encontraram uma média de 11,2 veias por perna o que também difere das citações da literatura em relação à ultra-sonografia dessas veias.

Estudos realizados em pacientes com TEP, em $42 \%$ deles foram encontrados trombos somente em veias soleares, relatando ainda, que a TVP foi a fonte de embolia pulmonar quando havia trombos com mais de $7 \mathrm{~mm}$ de diâmetro somente em veias soleares 9 . Um estudo prospectivo em 219 membros inferiores de 185 pacientes de 22 a 96 anos com trombose somente em veias gastrocnêmias e soleares, usando eco-Doppler, detectou trombos somente em veias soleares em $77,8 \%{ }^{10}$

Como se pôde observar, os quadros clínicos de TVP e TEP estão mais relacionados com as veias soleares do que com quaisquer outras veias do membro inferior. Esses fatos sempre foram referidos, porém sem haver qualquer citação ou valorização do número de veias soleares. Tal quantidade dessas veias torna-as mais importantes que o já considerado na literatura, no que se refere a etiopatogenia das doenças trombo-embólicas nos membros inferiores, pois torna-se óbvio que quanto maior for o número de veias soleares, maior é a probabilidade de existirem mais locais acometidos com trombose. Ressalte-se ainda que um aspecto importante das TVP é a sua tendência à recidiva em conseqüência de diagnóstico tardio ou tratamento inadequado. A incidência de TVP nos MMII é tão alta que há necessidade de um exame apurado de rotina para se fazer um diagnóstico precoce e, portanto, há que se valorizar e, principalmente, investigar minuciosamente essas veias, tanto clinicamente quanto através de métodos invasivos, como a clássica angiografia e não-invasivos como a pletismografia e a ultra-sonografia de membros inferiores, para diagnosticar precocemente e tratar com precisão. 


\section{Conclusão}

I - A drenagem venosa do músculo sóleo é realizada por um número de veias soleares muito maior do que o citado na literatura.

2 - As veias soleares localizam-se, freqüentemente, nos setores súpero-lateral, médio-medial e médio-lateral.

3 - As veias soleares terminam, comumente, em veias tibiais posteriores, fibulares e veias comunicantes.

Conflito de interesse: não há.

\section{SUMMARY}

\section{SOLEUS VEINS: ANATOMIC BASIS AND THEIR ROLE IN THE ORIGIN OF DEEP VENOUS LOWER LIMB THROMBOSIS}

Objective. Study of the number, sectorization and termination of the soleus veins.

Methods. Meticulous, stratigraphical, anatomical dissections were carried out in the posterior crural region of 100 legs of 50 fresh cadavers. Those belonging to subjects with congenital or acquired pathologies in the lower limbs were disregarded. After the skin was reflected on both sides, dissection of superficial and perforating veins, was performed. Then reflection of the subcutaneous tissue and fascia, detachment and reflection of the gastrocnemius and plantaris muscles, detachment of the tibial origin of the soleus muscle, differentiation of the soleus veins and study of morphometric parameters were carried out. The region was divided into six sectors: superior-medial, superior-lateral, mediomedial, medio-lateral, inferior-medial and inferior-lateral. Data obtained from Wilcoxon and Friedman nonparametric tests were utilized for statistical analysis.

RESULTS. In the dissected legs 4679 soleus veins were found. The sector with the greatest number of soleus veins was the superior-lateral (1529 veins - 32.7\%), followed by the mediomedial (1.256 veins - 26.8\%) and the mediolateral sectors (975 veins - 20.8\%). The extremities drained into communicant veins (1.207 veins - 25.8\%), posterior tibial veins (964 veins 20.6\%), peroneal veins (709 veins - 15.2\%) and into 32 other types (1.799 veins - 38.4\%).

CONCLUSION. The venous drainage of the soleus muscle is carried out by a great number of soleus veins which are frequently located in the superior-lateral, mediomedial and mediolateral sectors, more often going into the posterior tibial, peroneal and communicant veins. [Rev Assoc Med Bras 2007; 53(4): 305-10]

KEY wORDs: Veins. Muscle. Skeletal. Lower extremity. Humans. Anatomy.

\section{REFERÊNCIAS}

I. Loitz BJ. The morfology of the human soleus muscle [M.Sc.]. Los Angeles: University of California; 1980.

2. Testut $L$, Latarjet $A$. Venas. In: Tratado de anatomía humana. Barcelona: Salvat; 1959. v.2, p.402-5I0.
3. Pernkopf E. Miembros inferiores. In: Anatomía topográfica humana. Texto y Atlas para la disección por regiones y planos. Barcelona: Labor; 1955.v.2: p.II2-44.

4. Ukhov YI. The veins of the soleus and their relations to the organ structure. Arq Anat Histol Embriol. 1974;67(7): 104-10.

5. Abramova AA, Chilaya SM. Structure of venous sinuses of $m$. soleus and their role in origin of thromboses in deep veins of lower extremities. Arq Anat Histol Embriol. 1967;53(9):63-7.

6. Mayall RC, Mayall ACDG, Mayall JC, Mayall LCDG, Vite LJ, Pires CT, et al. Venas soleares y gemelas. Flebología. 1988; I (2):27-36.

7. Sequeira CMG, Mayall RC, Mayall ACDG. Estudo morfológico quantitativo comparativo entre a dissecção de veias soleares em pernas formolizadas e à fresco. J Vasc Bras. 2003;2(supl I):SI28.

8. Sevitt S, Gallagher N. Venous thrombosis and pulmonary embolism. A clinico-pathological study in injured and burned patients. Brit J Surg. 1961:48:475-89.

9. Ohgi S, Tachibana M, Ikebuchi M, Kanaoka Y, Maeda T, Mori T. Pulmonary embolism in patients with isolated soleal vein thrombosis. Angiology. 1998;49(9):759-64.

10. MacDonald PS, Kahn SR, Miller N, Obrand D. Short-term natural history of isolated gastrocnemius and soleal vein thrombosis. J Vasc Surg. 2003;37(3):523-7.

1 I. Zicot M, Caro CG. Occurrence of thrombi in calf veins: association with vein size and local venous haemodynamics. Clin Sci Mol Med. 1975;48(I):2.

12. Sequeira CMG. Estudo anatômico das veias soleares no homem [tese]. São Paulo: Escola Paulista de Medicina, Universidade Federal de São Paulo; 2005

13. Siegel S, Castellan Jr. NJ. Nonparametric statistics. $2^{\text {nd }}$ ed. New York: McGraw-Hill; 1988.

14. Dodd H, Cockett FB. Anatomy of the veins of the lower limb. In: The pathology and surgery of the veins of the lower limb. $2^{\text {nd }}$ ed. Edinburgh: Churchill Livingstone; 1976. p.18-24.

15. Kwakye LB. Gross anatomy of the soleus veins. Acta Morphol Neerl Scand. |97|-1972;9(2):28|-94.

16. Van Limborgh J, Kwakye LB. Anatomie normale des veines soleaires chez les personnes agées. Phlébologie. 1975;28(2):273-9.

17. Raveendran SS, Kumaragama KGJL. Arterial supply of the soleus muscle: anatomical study of fifty lower limbs. Clin Anat. 2003; 16(3):248-52.

18. Nicolaides AN, Kakkar W, Renney JTG. The soleal sinuses: origin of deep vein thrombosis. Brit J Surg. 1970;57:860.

19. Nicolaides AN, Kakkar W, Field ES, Spindler J. Soleal veins and stasis during operation. Brit J Surg. 1972;59(4):304.

20. Mayall JC, Mayall ACDG, Mayall RC, Ferreti UR, Bertolotti JG. Varices of the soleus veins- diagnosis and treatment. Folia Angiol. 1 974;22(1): 1-4.

21. Mayall RC, Mayall ACDG, Mayall JC. Soleus and gastrocnemius varicose veins. Medical and surgical treatment. J Cardiovasc Surg. 1989;30( I):70.

22. Sequeira CMG, Martins FG, Andrade JA, Mayall ACDG, Mayall RC. Estudo flebográfico das veias soleares. Rev Angiol Cir Vasc. 2005; I ( I): I 5-23. 